\title{
Inappropriate Discharge on Bronchodilators and Acid-Blocking Medications After ICU Admission: Importance of Medication Reconciliation
}

\author{
Andrey Pavlov MD, Rostislav Muravyev MD, Yaw Amoateng-Adjepong MD PhD, \\ and Constantine A Manthous MD
}

\begin{abstract}
BACKGROUND: Previous studies suggest that some medications, including proton pump inhibitors and $\beta$-agonist inhalers, are administered to hospitalized patients and sometimes continued without indications. Medication reconciliation has been offered as one mechanism to reduce the frequency of such medication errors and is now mandated by the Joint Commission (NPSG.03.06.01). We hypothesized that (1) $\beta$ agonists and acid-blocking medications are prescribed following critical illness without indications, and (2) medication reconciliation can reduce the frequency of inappropriate continuation of these agents. The study was carried out in a 414-bed community teaching hospital affiliated with the University of Connecticut Medical School. All subjects were admitted to the ICU between February and April 2012 (physician-driven reconciliation) and between July and September 2012, just following implementation of pharmacy technician-driven medication reconciliation. This was a retrospective cohort study. METHODS: Medical records of all subjects were reviewed using a uniform data extraction tool. Demographic information, clinical data, in-patient and out-patient medications (before and following hospital discharge), and outcomes were recorded. RESULTS: Prior to pharmacy technician-administered, physician-confirmed medication reconciliation, 253 ICU subjects were compared to 291 subjects admitted to the ICU after initiation of this process. There were no differences in admission type, stay, history of coronary artery disease, requirements for mechanical ventilation, or length of mechanical ventilation between groups. Rates of discharge on bronchodilators $(8.9$ vs $4.2 \%, P=.09)$ or acid blockers $(19.1$ vs $11.2 \%, P=.05)$ without clinical indications were lower with pharmacy technician-driven, physician-confirmed medication reconciliation than with routine physician-driven medication reconciliation. Multiple logistic regression analyses demonstrated a significant association of mechanical ventilation with inappropriate discharge on both bronchodilators and acid blockers. Pharmacy technician-driven medication reconciliation tended to reduce these errors. CONCLUSIONS: In our hospital, acid blockers and bronchodilators were often continued inappropriately following critical illness. The specific pharmacy technician-driven method of medication reconciliation deployed in our hospital reduced by half but did not eliminate this medication error. Key words: bronchodilator; proton pump inhibitor; histamine antagonist; mechanical ventilation; medication reconciliation; medication error. [Respir Care 2014;59(10):1524-1529. (ㅇ 2014 Daedalus Enterprises]
\end{abstract}

\footnotetext{
Drs Pavlov, Muravyev, and Manthous were affiliated with the Department of Internal Medicine, Hospital of Central Connecticut, New Britain, Connecticut, and University of Connecticut School of Medicine, Farmington, Connecticut. Dr Amoateng-Adjepong is affiliated with Bridgeport Hospital, Bridgeport, Connecticut, and Yale University School of Medicine, New Haven, Connecticut.
}

\author{
The authors have disclosed no conflicts of interest. \\ Correspondence: Constantine A Manthous MD. E-mail: constantine \\ manthous@gmail.com.
}

DOI: $10.4187 /$ respcare. 02913 


\section{Medication Reconciliation After ICU Admission}

\section{Introduction}

Failure to reconcile medications at various transitions of care (ie, hospital admission, intrahospital transfer, and discharge) can cause substantial harm to patients and increases cost to the health care system. ${ }^{1,2}$ Acid-blocking medications $^{3-5}$ and aerosolized bronchodilators ${ }^{6}$ are often administered to mechanically ventilated patients. There is evidence that bronchodilators are administered without clinical indication $^{5}$ and that acid blockers are administered inappropriately to non-critically ill hospitalized patients. ${ }^{7-12} \mathrm{Up}$ to $55 \%$ of patients treated with acid blockers are discharged on them despite the lack of clinical indications for continued therapy. ${ }^{7}$ In this study, we hypothesized that pharmacy technician-driven, physician-confirmed medication reconciliation would reduce the frequency of this medication error.

\section{Methods}

\section{Study Design and Setting}

The study protocol was exempted from review by the institutional review board of the Hospital of Central Connecticut, a 414-bed hospital with 24 medical-surgical ICU beds. From May through June 2012, the hospital changed its medication reconciliation process. Prior to May 2012 (Epoch 1), all medication reconciliations were conducted using paper-based forms that were completed by the admitting physician or allied professional (resident physician, advanced practicing nurse, or physician assistant) within $48 \mathrm{~h}$ of hospital admission. The medication list was included in all dictated formal admission notes and approved/confirmed by the admitting attending physician. Just prior to discharge, attending physicians referenced the formal admission note and compared it with medications administered in the hospital to formulate a list of discharge medications and prescriptions that were delineated in the dictated discharge note. After May 2012 (Epoch 2), medications taken prior to hospital admission were compiled and recorded by emergency room pharmacy technicians who interviewed subjects, or associates accompanying subjects (when subjects were incapable), and reviewed previous discharge notes and local out-patient pharmacy records available through a voluntary confidential shared database. A final list of prior-to-admission medications was entered in an electronic medical record, which was reviewed and modified/approved by the admitting attending physician of record within $48 \mathrm{~h}$. In addition, after May 2012, in-hospital transfers required that attending physicians review both pre-admission and in-patient medication lists and review the reconciled final list (created by a discharging nurse) with the subject at the time of

\section{QUICK LOOK}

\section{Current knowledge}

Failure to reconcile medications at transitions of care increases medication errors and costs to the health care system. In mechanically ventilated patients, $\beta$-agonist inhalers and proton pump inhibitors have been identified as medications commonly ordered without indications. The Joint Commission requires medication reconciliation at patient discharge.

\section{What this paper contributes to our knowledge}

In a single center study, bronchodilators and proton pump inhibitors were often continued following resolution of critical illness without indication. A pharmacist-led reconciliation program reduced inappropriate continuation of these medications by $>50 \%$ but did not eliminate the problem.

hospital discharge. The same list was transcribed in the hospitalization discharge summary.

\section{Data Extraction}

The ICU's admission/discharge log book identified patients admitted to the ICU during 3 mo (February 1 through April 30, 2012) prior to and 3 mo (July 1 through September 30, 2012) following the new reconciliation process. Patients transferred to the ICU more than once during the same admission were counted only once. Patients who died during their admissions or were not discharged at the time of data extraction were also excluded. Demographic (age, gender) and clinical (comorbidities; type of admission; primary diagnosis; stay; days requiring mechanical ventilation; type of respiratory failure if present; administration of acid-suppressive therapy or bronchodilators before admission and during mechanical ventilation; discharge medications, ie, acid blockers or bronchodilators) data were extracted and recorded for all subjects.

Pre-admission and discharge medications for Epoch 1 were ascertained using the dictated formal admission and discharge notes. For Epoch 2, the pharmacy techniciancompiled, physician-confirmed pre-admission medications and the discharge medications listed in the nurse-signed in-patient clinical summary were reviewed, and medications were recorded.

The acid-blocking medications considered were proton pump inhibitors, histamine- 2 blockers, and sucralfate. The inhaled bronchodilators considered were $\beta$ agonists with or without corticosteroid-containing preparations. Patients not treated with acid blockers or bronchodilators prior to 
Table 1. Demographic and Outcomes of Subjects

\begin{tabular}{|c|c|c|c|c|}
\hline & Epoch 1 & Epoch 2 & Combined & $P$ \\
\hline Total screened, $n$ & 350 & 353 & 703 & \\
\hline Not counted, $n$ & 97 & 62 & 159 & \\
\hline Met criteria for inclusion, $n$ & 253 & 291 & 544 & \\
\hline Age, y & $65.5 \pm 17.2$ & $62.4 \pm 18.5$ & $63.8 \pm 18.0$ & .04 \\
\hline Male, $n(\%)$ & $152(60)$ & $149(51)$ & $301(55)$ & .04 \\
\hline No. of comorbidities & 3.5 & 2.7 & 3.1 & .04 \\
\hline Coronary artery disease, $n$ & 58 & 76 & 134 & .39 \\
\hline Medicine service, $n(\%)^{*}$ & $200(79)$ & $199(68)$ & $399(73)$ & .06 \\
\hline Stay, d & 11.4 & 9.4 & 10.3 & .06 \\
\hline Required ventilation, $\%$ & 33 & 25 & 29 & .07 \\
\hline Duration of ventilation, $\mathrm{d}$ & 9.7 & 5.5 & 7.7 & .06 \\
\hline Mortality, \% & 20.6 & 13.2 & 20.6 & .006 \\
\hline Combined, $n$ & 253 & 291 & 544 & \\
\hline Discharged inappropriately on bronchodilators, $n$ & 17 & 9 & 26 & .09 \\
\hline Discharged inappropriately on acid blockade, $n$ & 36 & 20 & 56 & .05 \\
\hline Discharged inappropriately on both, $n$ & 7 & 5 & 12 & .59 \\
\hline Discharged inappropriately on either, $n$ & 46 & 24 & 70 & .006 \\
\hline Requiring mechanical ventilation, $n$ & 83 & 74 & 157 & \\
\hline Discharged inappropriately on bronchodilators, $n$ & 12 & 6 & 18 & .32 \\
\hline Discharged inappropriately on acid blockade, $n$ & 16 & 9 & 25 & .32 \\
\hline Discharged inappropriately on both, $n$ & 5 & 5 & 10 & .23 \\
\hline Discharged inappropriately on either, $n$ & 23 & 10 & 33 & .045 \\
\hline Not requiring mechanical ventilation, $n$ & 170 & 217 & 387 & \\
\hline Discharged inappropriately on bronchodilators, $n$ & 5 & 3 & 8 & .48 \\
\hline Discharged inappropriately on acid blockers, $n$ & 20 & 11 & 31 & .03 \\
\hline Discharged inappropriately on both, $n$ & 2 & 0 & 2 & $>.99$ \\
\hline Discharged inappropriately on either, $n$ & 23 & 14 & 37 & .03 \\
\hline
\end{tabular}

* Remaining non-medical subjects were surgical patients. Subjects who were transferred to the ICU more than once during the same admission were counted only once. Subjects who died during admission or were not discharged at the time of data extraction were excluded.

admission but who were discharged on them and those who had received them prior to admission but were discharged without them (for no clear reason) were deemed discordant. Paper medical records (physician progress notes, respiratory care data) of discordant cases were reviewed in detail to examine whether patients had any clinical indications for discharge on acid blockers or bronchodilators. Acid blockades, peptic ulcers, or new gastroesophageal refluxes diagnosed any time during hospital admissions were deemed appropriate indications. Bronchodilators, newly diagnosed obstructive lung diseases, wheezing recorded by physician clinical examinations, and elevated airway resistance (during mechanical ventilation $>15 \mathrm{~cm} \mathrm{H}_{2} \mathrm{O} / \mathrm{L} / \mathrm{s}$ ) were deemed appropriate.

Analyses were performed using OpenEpi 2.3.1 (Open Source Epidemiologic Statistics for Public Health, www.openepi.com) and Epi Info software. ${ }^{13}$ Continuous variables are reported as means $\pm \mathrm{SD}$. Means were compared using non-paired Student's $t$ test or analysis of variance. Categorical variables and proportions were compared with Fisher exact tests. Rates of inappropriate medication discordance during Epoch 1 were compared to Epoch 2.
Multiple logistic regression analyses were used to adjust for potential confounders. Independent variables for regression models were chosen based on biological plausibility and if differences between epochs were detected using univariate methods. A $P$ value of $<.05$ was considered statistically significant.

\section{Results}

A total of 350 subjects received ICU care during Epoch 1 compared to 353 in Epoch 2. The combined cohort had a mean age of $63.8 \pm 18.0 \mathrm{y} ; 55 \%$ were male; $73 \%$ were medical admissions; and mortality was $20.6 \%$. In-hospital mortality rate was higher in Epoch 1 compared to Epoch 2 (20.6 vs $13.2 \%, P=.006$ ). Of the 703 ICU admissions in the study period, 544 met the inclusion criteria (Table 1). Epoch 1 subjects were more likely to be male (60 vs 51\%, $P=.04)$, were older $(65.5 \pm 17.2$ y vs $62.4 \pm 18.5 \mathrm{y}$, $P=.04)$, and had more comorbidities ( 3.5 vs $2.7, P=.04$ ) (Table 1) compared to Epoch 2 subjects.

In Epoch 1, 192 of 253 (76\%) subjects were not on bronchodilators at the time of admission. Of these, 25 
Table 2. Unconditional Multiple Logistic Regression Analyses Examining Predictors of Inappropriate Discharge on Bronchodilators

\begin{tabular}{lcc}
\hline \hline \multicolumn{1}{c}{ Predictor } & $\begin{array}{c}\text { Adjusted } \\
\text { Odds Ratio }\end{array}$ & $95 \%$ CI \\
\hline$\geq 65$ y old & 1.4 & $0.6-3.5$ \\
$\geq$ 15-d hospital stay & 2.4 & $0.98-5.8$ \\
Coronary artery disease & 1.4 & $0.5-4.0$ \\
Presence of other comorbid conditions & 2.1 & $0.4-10.9$ \\
Epoch 1 (vs Epoch 2) & 2.4 & $0.98-5.9$ \\
Mechanically ventilated & 4.4 & $1.7-11.1$ \\
Surgical (vs medical) service & 3.1 & $1.3-7.3$ \\
\hline
\end{tabular}

(13.0\%) were discharged on bronchodilators and 17 (8.9\%) without discernible indications. Two of the 61 subjects who were on bronchodilators at the time of admission were not discharged on them. In Epoch 2, 216 of 291 (74\%) subjects were not on bronchodilators at the time of admission. Of these, $12(5.6 \%)$ were discharged on bronchodilators, and $9(4.2 \%)$ were discharged inappropriately. Nearly all $(73 / 75,94.7 \%)$ of the 75 subjects on bronchodilators at time of admission were discharged on them. From the multiple logistic regression analyses (Table 2), subjects were more likely to be inappropriately discharged on bronchodilators if they had been mechanically ventilated (adjusted odds ratio [OR] 4.4, 95\% CI 1.7-11.1) or were on the surgical (adjusted OR 3.1, 95\% CI 1.3-7.3) rather than medical service. Adjusted for comorbid conditions, type of service, ventilation status, and age, there was a tendency for inappropriate discharges on bronchodilators to be associated with extended hospital stay ( $\geq 15 \mathrm{~d}$, adjusted OR 2.4, 95\% CI 0.98-5.8) and Epoch 1 admission (adjusted OR 2.4, 95\% CI 0.98-5.9). There was no association between age, gender, or comorbid conditions and inappropriate discharge on bronchodilators.

In Epoch 1, 188 of 253 (74\%) subjects were admitted who were not on acid blockers at the time of admission. Of these, $50(26.6 \%)$ were discharged on acid blockers, 36 (19.1\%) of them inappropriately. Of the 65 (of 253, 26\%) subjects on acid blockers at the time of admission, 10 (15.4\%) were not discharged on acid blockers. In Epoch 2, 178 of $291(61 \%)$ subjects were admitted who were not on acid blockers at the time of admission; 26 (14.6\%) were discharged on acid blockers, 20 (11.2\%) of them inappropriately. One-hundred twelve subjects were on acid-blocking drugs at the time of admission. Of these, $10(8.9 \%)$ were not discharged on acid-blocking drugs. From the multiple logistic regression analyses (Table 3), subjects were more likely to be inappropriately discharged on acid blockers if they were admitted in Epoch 1 (adjusted OR 2.5, 95\% CI1.4-4.7), had coronary artery disease (adjusted OR 3.4, 95\% CI 1.7-6.7), were mechanically ventilated (adjusted OR 1.9, 95\% CI 1.02-3.6), or had an extended
Table 3. Unconditional Multiple Logistic Regression Analyses Examining Predictors of Inappropriate Discharge on AcidBlocking Drugs

\begin{tabular}{lcr}
\hline \hline \multicolumn{1}{c}{ Predictor } & $\begin{array}{c}\text { Adjusted } \\
\text { Odds Ratio }\end{array}$ & 95\% CI \\
\hline$\geq 65$ y old & 1.1 & $0.6-2.1$ \\
Coronary artery disease & 3.4 & $1.7-6.7$ \\
4 or more other comorbid conditions & 0.5 & $0.2-0.9$ \\
$\geq$ 15-d hospital stay & 2.0 & $1.01-4.0$ \\
Epoch 1 (vs Epoch 2) & 2.5 & $1.4-4.7$ \\
Mechanically ventilated & 1.9 & $1.02-3.7$ \\
Surgical (vs medical) service & 1.4 & $0.8-2.7$ \\
\hline
\end{tabular}

hospital stay of $\geq 15 \mathrm{~d}$ (adjusted OR 2.0, 95\%CI 1.01 3.97).

Overall, patients inappropriately placed on bronchodilators were 6.3 times more likely to be placed on inappropriate acid blockers after adjusting for other factors (including mechanical ventilation during hospitalization, type of service, and comorbid conditions).

\section{Discussion}

This study suggests that some patients recovering from critical illness continued to receive acid blockers and bronchodilators inappropriately up to and following hospital discharge. Pharmacy technician-driven medication reconciliations during admission, followed by nurse-driven reconciliations at discharge, halved the number of patients discharged on these medications without medical indications. Mechanical ventilation during hospitalization emerged as an independent risk for this association.

Previous studies have demonstrated inappropriate use of bronchodilators in ventilated patients and acid blockers in non-critically ill hospitalized patients. Chang et $\mathrm{al}^{6}$ showed that 74 of 206 patients received bronchodilators during mechanical ventilation without clinical indications, but they did not follow patients to discharge. The published literature $^{7-16}$ on inappropriate acid blockade is much larger, and the relationship with ICU stay has been previously described in community and tertiary centers nationally and internationally. Of 357 ICU patients given acid blockers, $24 \%$ were discharged on them with no clinical indication. ${ }^{15}$ Of 248 consecutive patients treated in a surgical ICU, 237 began acid blockers in the unit, 60 were discharged from the hospital with them, and only 3 "had a compelling risk factor." $16 \mathrm{We}$ can only surmise that such perseverant treatment with bronchodilators and acid blockers is a medication error, an unintended artifact of critical care, most likely mechanical ventilation, where risks and costs are not offset by proven benefits.

Medication reconciliation is the process suggested to address such errors. We chose to focus on bronchodilators 
and acid blockers because they are known culprits for inappropriate use in hospitalized patients in various settings and countries. Interestingly, despite national mandates to improve medication reconciliations, ${ }^{1}$ there are very sparse data that demonstrate (any specific) methods that reduce harm to patients or even cost to the health care system. Some published studies present models suggesting opportunities for such benefits of medication reconciliation. ${ }^{17}$ Others demonstrate that careful medication reviews can find errors, ${ }^{17-20}$ but we could find no published study demonstrating that any form of reconciliation reduced patients' morbidity or mortality. In fact, there appears to be some concern expressed among scholars on how, in this fragmented medical system where patients can receive new medications from numerous specialists and subspecialists with no central clearinghouse of medication reconciliation, to define an accepted standard. ${ }^{21}$ Accordingly, we did not seek to determine here whether the subjects' medication reconciliations on admission were correct, but rather, given their admission medication list and medical illnesses prior to and during admission, whether they had clinical indications for receiving bronchodilators or acid-blocking medications. This is the first study we could find to demonstrate that medication reconciliation can substantially reduce this discharge medication error. The impact on patients' outcomes is uncertain except to suggest that half of the subjects went home with the risks and costs associated with bronchodilators and acid blockers with no discerned indication.

The impact of these medication errors on patient outcomes is uncertain, but both bronchodilators and acid blockers can cause complications. We included coronary artery disease in logistic regression models for perseverant acid blockers because we hypothesized that recent data suggesting the harm of proton pump inhibitors to patients with coronary artery stents ${ }^{12,22}$ might be applied with enhanced medication reconciliation to reduce the frequency of patients discharged on proton pump inhibitors without a history of gastrointestinal hemorrhage or other indications for acid blockade. We were surprised to find that the presence of coronary disease was highly associated with greater misuse of acid blockers, suggesting that the empiric practice of primary prophylaxis with acid blockers persists despite suggestions of harm. ${ }^{12,22} \mathrm{We}$ did not, however, ascertain details of subjects' coronary artery disease histories (eg, stent vs no stent, medications like aspirin or clopidogrel that may have prompted medication reconcilers to permit perseverant acid blockers). Similarly, we did not distinguish between acid blockers, some of which are believed to be safer when used with clopidogrel. This area deserves attention in future studies.

This study has several notable limitations. It is a small sample and the experience of a single small community hospital with idiosyncratic medication reconciliations both before and following modifications. Our study suggests that only this specific process of reconciliation was associated with reduced inappropriate prescription at discharge. Additionally, we cannot discount the possibility that period or seasonal trends accounted for the observed association. There were differences in demographics and outcomes of the 2 samples that we cannot explain, so it is possible that residual confounding accounts for the observed association. It is possible that medication reconciliation impacted the accuracy of medications taken prior to admission; indeed, we noticed a substantial and unexplained increase (from 28.5 in Epoch 1 to 39.2\% in Epoch 2) in subjects admitted on acid-blocking medications. Thus, systematic bias could have contributed to the observed results.

Despite these important limitations, there is still reason to believe that the results are real. First, the strong independent association of perseverant acid blockade and bronchodilator therapy makes sense because there are systemic drivers to initiate these medications (and indeed, 97\% were started during mechanical ventilation) but not to stop them. Second, greater attention to medication reconciliation more generally in Epoch 2, irrespective of the precise methodology, is a plausible cause for fewer perseverant medication errors. Third, this study design did not permit us to determine whether subjects admitted on these medications had appropriate indications for their continuation. Accordingly, some subjects may have lacked appropriate prior indications, and the medications were continued because our system of reconciliation does not require clinicians to interrogate whether pre-admission medications are appropriate. Thus, our study may underestimate the true rate of inappropriate acid blockade or bronchodilator therapy upon discharge.

In conclusion, this study demonstrates that some survivors of critical illness continued to receive bronchodilators and acid blockers without indications even after discharge from hospital and that this error is highly associated with mechanical ventilation. A hospital-wide, pharmacy technician-driven medication reconciliation process was associated with lower rates of discharge on these agents without indications. Future studies might determine additional mechanisms, perhaps formal stops of acid blockers and bronchodilators following mechanical ventilation or additional medication reconciliations when transferring from the ICU to wards, to further reduce or eliminate this error.

\section{REFERENCES}

1. The Joint Commission. National Patient Safety Goals. http://www. jointcommission.org/assets/1/6/2014_HAP_NPSG_E.pdf. Accessed April 28, 2014.

2. Mueller SK, Sponsler KC, Kripalani S, Schnipper JL. Hospital-based medication reconciliation practices: a systematic review. Arch Intern Med 2012;172(14):1057-1069. 


\section{Medication Reconciliation After ICU Admission}

3. Cook D, Guyatt G, Marshall J, Leasa D, Fuller H, Hall R, et al. A comparison of sucralfate and ranitidine for the prevention of upper gastrointestinal bleeding in patients requiring mechanical ventilation. Canadian Critical Care Trials Group. N Engl J Med 1998;338: 791-797.

4. Cook DJ, Reeve BK, Guyatt GH, Heyland DK, Griffith LE, Buckingham L, Tryba M. Stress ulcer prophylaxis in critically ill patients. Resolving discordant meta-analyses. JAMA 1996;275(4):308-314.

5. Institute for Healthcare Improvement. Ventilator Bundle. http://www. ihi.org/resources/pages/changes/implementtheventilatorbundle.aspx. Accessed April 28, 2014.

6. Chang LH, Honiden S, Haithcock JA, Das AM, Short KA, Nierman DM, Carson SS. Utilization of bronchodilators in ventilated patients without obstructive airways disease. Respir Care 2007;52(2):154158.

7. Ramirez E, Lei SH, Borobia AM, Piñana E, Fudio S, Muñoz R, et al. Overuse of PPIs in patients at admission, during treatment, and at discharge in a tertiary Spanish hospital. Curr Clin Pharmacol 2010; 5:288-297.

8. Heidelbaugh JJ, Inadomi JM. Magnitude and economic impact of inappropriate use of stress ulcer prophylaxis in non-ICU hospitalized patients. Am J Gastroenterol 2006;101:2200-2205.

9. Nardino RJ, Vender RJ, Herbert PN. Overuse of acid-suppressive therapy in hospitalized patients. Am J Gastroenterol 2000;95(11): 3118-3122.

10. van Vliet EP, Otten HJ, Rudolphus A, Knoester PD, Hoogsteden HC, Kuipers EJ, Siersema PD. Inappropriate prescription of proton pump inhibitors on two pulmonary medicine wards. Eur J Gastroenterol Hepatol 2008;20(7):608-612.

11. Glew CM. Rentier J. Use of proton pump inhibitors and other acid suppressive medications in newly admitted nursing facility patients. J Am Med Dir Assoc 2007;8(9):607-609.

12. Siller-Matula JM, Jilma B, Schrör K, Christ G, Huber K. Effect of proton pump inhibitors on clinical outcome in patients treated with clopidogrel: a systematic review and meta-analysis. J Thromb Haemost 2010;8(12):2624-2641.

13. Dean AG, Arner TG, Sunki GG, Friedman R, Lantinga M, Sangam $\mathrm{S}$, et al. Epi $\operatorname{Info}^{\mathrm{TM}}$, a database and statistics program for public health professionals. Centers for Disease Control and Prevention, Atlanta, Georgia, 2008. http://wwwn.cdc.gov/epiinfo. Accessed April 28,2014

14. Thomas L, Culley EJ, Gladowski P, Goff V, Fong J, Marche SM. Longitudinal analysis of the costs associated with inpatient initiation and subsequent outpatient continuation of proton pump inhibitor therapy for stress ulcer prophylaxis in a large managed care organization. J Manag Care Pharm 2010;16(2):122-129.

15. Wohlt PD, Hansen LA, Fish JT. Inappropriate continuation of stress ulcer prophylactic therapy after discharge. Ann Pharmacother 2007; 41(10):1611-1616.

16. Murphy CE, Stevens AM, Ferrentino N, Crookes BA, Hebert JC, Freiburg CB, Rebuck JA. Frequency of inappropriate continuation of acid suppressive therapy after discharge in patients who began therapy in the surgical intensive care unit. Pharmacotherapy 2008;28(8): 968-976.

17. Karnon J, Campbell F, Czoski-Murray C. Model-based cost-effectiveness analysis of interventions aimed at preventing medication error at hospital admission (medicine reconciliation). J Eval Clin Pract 2009;15(2):299-306.

18. Beckett RD, Crank CW, Wehmeyer A. Effectiveness and feasibility of pharmacist-led admission medication reconciliation for geriatric patients. J Pharm Pract 2012;25(2):136-141.

19. Lubowski TJ, Cronin LM, Pavelka RW, Briscoe-Dwyer LA, Briceland LL, Hamilton RA. Effectiveness of a medication reconciliation project conducted by PharmD students. Am J Pharm Educ 2007; 71(5):94.

20. Miller SL, Miller S, Balon J, Helling TS. Medication reconciliation in a rural trauma population. Ann Emerg Med 2008;52(5):483-91.

21. van Sluisveld N, Zegers M, Natsch S, Wollersheim H. Medication reconciliation at hospital admission and discharge: insufficient knowledge, unclear task reallocation and lack of collaboration as major barriers to medication safety. BMC Health Serv Res 2012;12: 170.

22. Cayla G, Hulot JS, O'Connor SA, Pathak A, Scott SA, Gruel Y, et al. Clinical, angiographic, and genetic factors associated with early coronary stent thrombosis. JAMA 2011;306(16):1765-1774. 